\author{
T.V. Sleptsova ${ }^{1}$, E.I. Alexeeva ${ }^{1}{ }^{2}$, R.V. Denisova ${ }^{1}$, S.I. Valieva ${ }^{1}$, T.M. Bzarova ${ }^{1}$, K.B. \\ Isaeva $^{1}$, E.V. Mitenko ${ }^{1}$ \\ ${ }^{1}$ Scientific Center of Children's Health, Moscow, Russian Federation \\ ${ }^{2}$ First Sechenov Moscow State Medical University, Russian Federation
}

\title{
Experience of methotrexate use in a patient with systemic juvenile idiopathic arthritis
}

\section{Author affiliation:}

Ekaterina Iosifovna Alexeeva, $\mathrm{PhD}$, Professor, head of the rheumatology department at the $\mathrm{SCCH}$, dean of the pediatrics faculty at the First Sechenov MSMU

Address: Moscow, Lomonosovskiy Av. 2/1, 119991, tel.: (499) 134-02-97, e-mail: alekatya@yandex.ru

Article received: 02.06 .2013 . Accepted for publication: 30.09 .2013 .

The article presents a case of early onset of systemic juvenile arthritis with active articular syndrome, severe systemic manifestations and high level of laboratory disease activity indicators. It describes successful use of methotrexate for intramuscular administration in the dose of $25 \mathrm{mg} / \mathrm{m}^{2}$ of body surface per week. Systemic disease manifestations terminated in a child after 1 month of treatment, acute inflammatory articular alterations, arthralgiae and morning stiffness disappeared and laboratory disease activity indicators reduced after 6 months; range of motions completely recovered in 4 out of 6 affected joints after 12 months of treatment. Inactive disease state and remission were registered after 6 and 12 months of treatment, respectively. Remission has been present for 24 months.

Keywords: children, systemic juvenile idiopathic arthritis, methotrexate, intramuscular administration.

Systemic juvenile idiopathic arthritis (sJIA) is a multifactorial disease characterized by generalized lesion of musculoskeletal system and involvement of internal organs in the immunopathological process [1].

Treatment of sJIA is a serious problem of pediatric rheumatology due to low efficacy of methotrexate and tumor necrosis factor (TNF) $\alpha$ inhibitors for this form of the disease $[1,2]$. The most often affected joints in children are large and medium joints, particularly, knee, ankle, wrist, elbow, hip joints; less often - smaller joints of hands and feet. Proliferative-exudative articular alterations quickly result in the development of persistent deformations and contractures, amyotrophy and hypotrophy [2]. JIA is usually progressive and results in early incapacitation and reduction in life quality of patients. Moreover, many authors report that JIA reduces life expectancy of patients by 10 years on the average, though it may be comparable to the population values in case of the prolonged controlled treatment [3].

Moreover, early diagnostics and timely beginning of adequate immunosuppressive therapy prior to the development of destructive articular alterations and incapacitation of the patient may change the prognosis, reduce incapacitation stage and restore the child to productive life.

It should be noted that prescription of immunosuppressive therapy is the basis of pathogenetic approach to treatment of juvenile arthritis [4-9].

Methotrexate has a special place among immunosuppressive drugs. Methotrexate is acknowledged as the "gold standard" for rheumatoid arthritis treatment in adults and of JIA in children; efficacy of all the new drugs must not be lower than of methotrexate $[10,11]$.

We would like to bring to your attention case report of a boy with early onset of systemic JIA in order to demonstrate efficacy of early prescription of methotrexate for parenteral administration. Patient A., 4 years of age, has been being observed at the rheumatology department of the Scientific Center of Children's Health for 2.5 years; the child of the $2^{\text {nd }}$ pregnancy and the $1^{\text {st }}$ out of the twins; born prematurely in the $33^{\text {rd }}$ gestation week. Birth weight $-850 \mathrm{~g}$, body length -27 $\mathrm{cm}$. The child remained at the infantile pathology department with diagnosis "Intrauterine 
growth retardation" in the early neonatal period. The child has been fed artificially since birth. Preventive vaccination was conducted according to the individual schedule until the age of 1 year; the child has been relieved from vaccination due to health reasons since then. Hereditary history in terms of rheumatic diseases was not compromised.

The boy contracted the disease at the age of 1 year 1 month, when swelling developed on the right wrist joint in the setting of an acute respiratory infection. At the age of 1 year 4 months, fever up to $39^{\circ} \mathrm{C}$, linear rash on the body, intensifying at severe fever and swelling of both knee and ankle joints were observed. X-ray examination did not reveal alterations in knee joints. Nonsteroid anti-inflammatory drug (diclofenac sodium) was prescribed for arthritis. Positive dynamics of the child's condition was not achieved: fever and swelling of joints persisted; the child refused to stand up. Clinical blood analysis revealed leukocytosis up to $11 \times 10^{9} / 1$, increase in erythrocyte sedimentation rate (ESR) up to $53 \mathrm{~mm} / \mathrm{h}$; immunological blood analysis - increase in serum concentration of C-reactive protein (CRP) up to 9 norms. The boy was hospitalized to the local inpatient hospital, where he underwent complete examination: computed tomography (CT) of thoracic organs, paracentesis of marrow and analysis of antibodies to arthritogenic infections in blood serum. Oncohematological and infectious processes, including specific infectious process, were ruled out. CT of knee joints revealed synovitis of both knee joints. Diagnosis "Systemic juvenile idiopathic arthritis" was established on the basis of clinicalanamnestic data. The patient was prescribed antibacterial therapy, pulse methylprednisolone therapy in the dose of $10 \mathrm{mg} / \mathrm{kg}$ per infusion, \#5. A short-term positive effect was observed in the setting of the treatment; the child's condition deteriorated considerable after 3 weeks: hectic fever 2-3 times a day, swelling of knee, ankle and both wrist joints, intense articular pains; the child would not stand up and almost all time cried of pain.

Given the insufficient effect of the conducted treatment, the child was hospitalized to the SCCH rheumatology department for examination and therapy correction.

The child's condition at admission was considered severe due to hectic fever pain, restriction of motions in knee, ankle and wrist joints and morning stiffness for up to 3 hours. Skin pallor, unstable linear non-pruritic rash on the body and lymphadenopathy attracted attention at examination; we revealed exudative-proliferative alterations in both knee, ankle and wrist joints, painful flexion contractures of knee joints and restriction of motions in all the affected joints were revealed (pic. 1-3). Chemical blood analysis as part of the examination revealed hypochromic anemia: hemoglobin - $97 \mathrm{~g} / 1$, leukocytosis $-23.5 \times 10^{9}$, ESR increase up to 57 $\mathrm{mm} / \mathrm{h}$; immunological blood analysis - increase in the serum immunoglobulin (Ig) G levels to $17.5 \mathrm{~g} / 1$ (norm being $\leq 14.6$ ), in the CRP level - to $62 \mathrm{mg} / 1$ (norm being $\leq 5$; tb.). Ultrasound examination (US) revealed hepatosplenomegaly and ruled out serosites. Radiography revealed cystic osteoporosis of articular surfaces and narrowing of joint spaces. US visualized fee fluid in upper recesses of both knee joints, unevenness of the cortical layer of the joint-forming bones and hyperechoic excrescences in the structure of cartilaginous tissue; all the alterations were more pronounced in the right knee joint. The boy was examined by an ophthalmologist who ruled the possibility of uveitis.

Pic. 1. The patient's general appearance before methotrexate therapy.

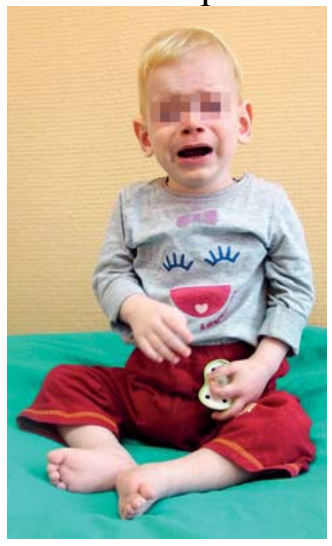


Pic. 2. Exudative-proliferative alterations in knee and ankle joints before methotrexate therapy.

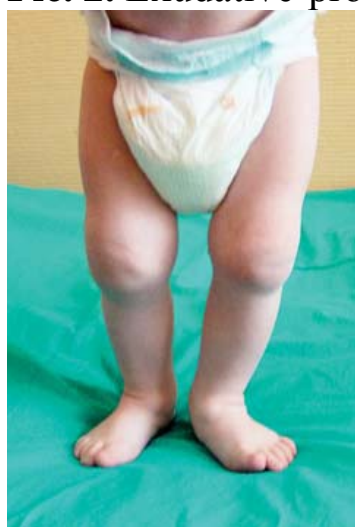

Pic. 3 A-D. Exudative-proliferative alterations in ankle joints before methotrexate therapy.

A

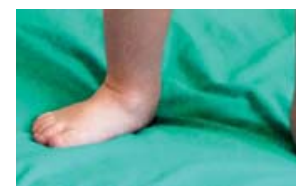

C

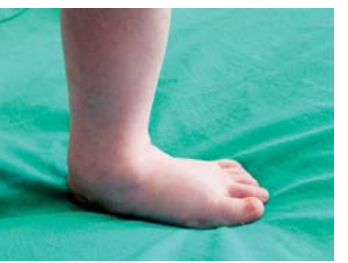

B

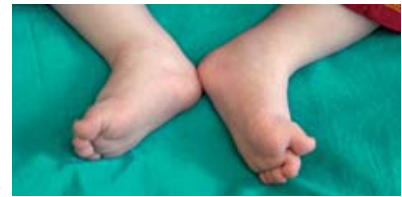

D

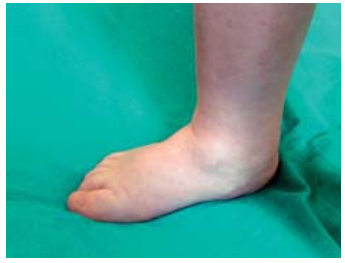

Table. Dynamics of clinical and laboratory indicators of the disease's activity in the setting of parenteral intake of methotrexate in the dose of $25 \mathrm{mg} / \mathrm{m}^{2}$ per week in patient A.

\begin{tabular}{|c|c|c|c|c|c|}
\hline Indicators & $\begin{array}{c}\text { Before } \\
\text { methotrexate } \\
\text { therapy }\end{array}$ & $\begin{array}{c}\text { After } 1 \\
\text { month of } \\
\text { methotrexate } \\
\text { therapy }\end{array}$ & $\begin{array}{c}\text { After } 3 \\
\text { months of } \\
\text { methotrexate } \\
\text { therapy }\end{array}$ & $\begin{array}{c}\text { After } 6 \\
\text { months of } \\
\text { methotrexate } \\
\text { therapy } \\
\end{array}$ & $\begin{array}{c}\text { After } 12 \\
\text { months of } \\
\text { methotrexate } \\
\text { therapy }\end{array}$ \\
\hline Temperature, ${ }^{\circ} \mathrm{C}$ & 39.8 & 36.9 & 36.7 & 36.7 & 36.7 \\
\hline Hepatosplenomegaly & Present & Present & none & none & none \\
\hline Lymphadenopathy & Present & Present & none & none & none \\
\hline $\begin{array}{l}\text { Duration of morning } \\
\text { stiffness (in minutes) }\end{array}$ & 180 & 60 & 10 & none & none \\
\hline $\begin{array}{l}\text { Number of joints } \\
\text { with active arthritis }\end{array}$ & 6 & 6 & 4 & 0 & 0 \\
\hline $\begin{array}{lr}\begin{array}{l}\text { Number } \\
\text { with }\end{array} & \text { restricted } \\
\text { function } & \end{array}$ & 6 & 6 & 4 & 3 & 2 \\
\hline $\begin{array}{l}\text { Subjective evaluation } \\
\text { of the disease's } \\
\text { activity as per VAS } \\
\text { (in points) }\end{array}$ & 70 & 55 & 30 & 0 & 0 \\
\hline $\begin{array}{l}\text { Patient's subjective } \\
\text { evaluation of pain as } \\
\text { per VAS (in points) }\end{array}$ & 80 & 60 & 35 & 0 & 0 \\
\hline ESR (in $\mathrm{mm} / \mathrm{h}$ ) & 57 & 30 & 12 & 6 & 5 \\
\hline $\mathrm{Hb}($ in $\mathrm{g} / \mathrm{l})$ & 97 & 112 & 117 & 125 & 138 \\
\hline $\begin{array}{l}\text { Erythrocytes } \\
\left(\times 10^{12} / 1\right)\end{array}$ & 3.3 & 3.5 & 3.9 & 4.37 & 4.45 \\
\hline Platelets $\left(\times 10^{9} / 1\right)$ & 690 & 605 & 557 & 387 & 340 \\
\hline Leukocytes $\left(\times 10^{9} / 1\right)$ & 23.5 & 13.2 & 8.1 & 7.9 & 6.9 \\
\hline CRP (in $\mathrm{mg} / \mathrm{l} ; \mathrm{N} \leq 5$ ) & 62 & 34 & 5 & 3 & Less than 1 \\
\hline
\end{tabular}




\begin{tabular}{|l|c|c|c|c|c|}
\hline $\begin{array}{l}\text { IgG (in g/l; N - 5.0- } \\
\text { 14.7) }\end{array}$ & 17.5 & 16.0 & 14.9 & 12.1 & 9.8 \\
\hline Inactive disease stage & - & - & - & + & \\
\hline $\begin{array}{l}\text { Remission of the } \\
\text { disease }\end{array}$ & - & - & - & - & + \\
\hline $\begin{array}{l}\% \text { of improvement } \\
\text { according to the } \\
\text { ACR }_{\text {pedi }} \text { criteria }\end{array}$ & & & $50 \%$ & $90 \%$ & $90 \%$ \\
\hline
\end{tabular}

Note. VAS - visual analog scale (min - 0; max - 100), ESR - erythrocyte sedimentation rate, Hb - hemoglobin, $\mathrm{CRP}$ - C-reactive protein, $\mathrm{ACR}_{\text {pedi }}$ - pediatric criteria of the American College of Rheumatology.

Diagnosis "systemic juvenile idiopathic arthritis" was confirmed on the basis of anamnestic data, clinical presentation and results of the conducted laboratory and instrumental examination.

Thus, the patient was admitted to the department with systemic JIA, high activity, active systemic manifestations and polyarticular syndrome at 1.5 years of age.

It should be noted that methotrexate has a special place among immunosuppressive drugs either; it is the first and the most often prescribed drug for children with juvenile arthritis. The drug belongs to the group of antimetabolites. In terms of structure, methotrexate is similar to folic (pteroylglutamic) acid; the only difference is the replacement of amino group to carboxylic in the $4^{\text {th }}$ site of the pteridine acid and addition of a methyl group in the $10^{\text {th }}$ site of the 4 -aminobenzoic acid [9].

Methotrexate in the low and medium doses applied in rheumatology has primarily an antiinflammatory effect due to excessive accumulation of adenosine - purine nucleoside capable of having considerable anti-inflammatory effect due to interaction with specific adenosine receptors A2 on the surface of activated neutrophils [12]. Some pharmacological effects of methotrexate may be connected with its influence on synthesis of the polyamines required for proliferation of cells and protein synthesis, which also take part in the cell-mediated immune reactions [2, 13].

The data on the drug's influence on cytokine synthesis allow assuming that there is a shift in cytokine synthesis from Th1 (IL 2, IFN $\gamma$ ) to Th2 (IL 10) in the setting of therapy with low doses of methotrexate; this would explain the drug's anti-inflammatory and immunomodulating effects [2].

This conjecture explains pronounced anti-inflammatory and immunomodulating effects of low doses of the drug, which are especially obvious in case of the so called Th1-dependent diseases, such as rheumatoid arthritis. Another point of application of methotrexate's effects is inhibition of production of proteolytic enzymes (collagenase and stromelysin), which play an important role in the destruction of joints at rheumatoid arthritis. Finally, it has recently been observed that in vitro methotrexate stimulates differentiation of monocytes and expression of the Fas-antigen associated with intensification of release of anti-inflammatory cytokines (soluble antagonist IL 1 and pTNF-75p) and inhibition of IL $1 \mathrm{~b}$ synthesis. At the same time, intensification of differentiation of monocytes is associated with the increase in sensitivity of these cells to the TNF-induced apoptosis. Together, these data allow assuming that one of the possible mechanisms of methotrexate's anti-inflammatory action is associated with suppression of recruitment of immature and "inflammatory" monocytes from marrow to the inflammation site and reduction in the life cycle of these cells in the inflamed tissues [2, 13-17].

High spread of juvenile arthritis allowed conducting a large number of scientific trials in different countries, which formed a serious evidential basis of the drug's efficacy [14-21]. Clinical trials of methotrexate's efficacy at juvenile arthritis indicated the drug's effect after several weeks of intake and high level of tolerance in the patients, who had previously responded only to the glucocorticoid therapy [15-18]. Randomized comparative trials showed that methotrexate in the dose of $10-15 \mathrm{mg} / \mathrm{m}^{2}$ is more effective than a placebo $[19,20]$ or other basic anti-inflammatory drugs [21].

The range of the methotrexate's doses effective when used in children is wide due to many factors, primarily, due to the drug's rapid clearance, which is especially rapid in infants [22]. 
As experience of applying baseline therapy with the drug was being accumulated, it appeared that some patients are resistant to the standard low doses. Due to pharmacokinetic peculiarities and data on the methotrexate's action mechanism, it was assumed that the use of the drug in increased doses and/or parenterally in this category of patients may be reasonable [23].

The multicenter randomized study of efficacy and safety of methotrexate therapy in medium (15$20 \mathrm{mg} / \mathrm{m}^{2}$ per week, not more than $20 \mathrm{mg} /$ week $)$ and high $\left(30 \mathrm{mg} / \mathrm{m}^{2}\right.$ per week, not more than 40 $\mathrm{mg} /$ week) doses in patients with polyarticular syndrome at JA brought to an end in 2004 was the largest in the decade past [24]. Even a 30\% improvement according to the pediatric criteria of the American College of Rheumatology $\left(\mathrm{ACR}_{\mathrm{pedi}}\right)$ could not be registered in 80 out of 595 patients treated with methotrexate in the dose of $8-12.5 \mathrm{mg} / \mathrm{m}^{2}$ per week. This group was divided into 2 subgroups: methotrexate dose was increased to $15 \mathrm{mg} / \mathrm{m}^{2}$ of body surface per week for the children of the first subgroup $(n=40)$; in the second group $(n=40)$ it was increased to $30 \mathrm{mg} / \mathrm{m}^{2}$. The drug was administered subcutaneously or intramuscularly. A 30\% improvement according to the $\mathrm{ACR}_{\text {pedi }}$ criteria was registered in $55-62 \%$ of the patients after 6 months of treatment; however, no statistically significant differences of the drug's efficacy and safety were revealed between the subgroups. Thus, the study showed that the optimal dose of methotrexate for children with juvenile arthritis is $15-20 \mathrm{mg} / \mathrm{m}^{2}$ of body surface per week intramuscularly or subcutaneously and that the therapy effect ought to be assessed only after 9-12 months of treatment. According to the authors, the efficacy of methotrexate therapy in medium and high doses is the same, which is why simply increasing the dose over $20 \mathrm{mg} / \mathrm{m}^{2}$ per week is not enough to improve efficacy of the conducted therapy. We may assume that simply escalating the dose over a certain limit does not lead to the desirable effect; possibly, change of the mode of administration may be a factor for overcoming refractoriness.

In a different trial, Czech scientists proved that there is significant difference in bioavailability of methotrexate between oral intake and subcutaneous administration in children; significant difference in the drug's absorption between peroral intake and parenteral intake starts manifesting itself from the dose of more than $10 \mathrm{mg} / \mathrm{m}^{2}$ [23]. That is why parenteral (subcutaneous, intramuscular) administration is more effective.

Comparative trials of methotrexate's efficacy depending on the mode of administration are of interest. E.g., efficacy of subcutaneous administration of methotrexate to children with insufficient response to the oral intake was assessed in Canada. The trial involved 61 children with juvenile arthritis (43 girls, 18 boys; 8 had systemic arthritis, 25 - polyarthritis, 14 oligoarthritis, 5 - enthesitis-associated arthritis, 4 - nondifferentiable arthritis). Methotrexate for subcutaneous administration was prescribed to 38 children due to lack of effect of the oral intake (13), insufficient efficacy (7) and nausea development (18) [25]. Condition improvement was registered in $77 \%$ of children after 3 months of treatment; methotrexate's hepatotoxicity was lower in the group of children receiving the drug parenterally (subcutaneously) than in the group of children with oral intake.

Many years of the drug's application in rheumatology allowed studying well the range of its side effects $[26,27]$. It has been established that efficacy/toxicity ratio is significantly higher in methotrexate than in any other basic antirheumatic drug.

Thus, methotrexate has been acknowledged as the "gold standard" for juvenile arthritis treatment: numerous trials showed that application of methotrexate in the dose of $15 \mathrm{mg} / \mathrm{m}^{2}$ of body surface per week allows reducing inflammatory activity of the rheumatic process. According to several trials, increase in the dose of the drug allows reducing the disease's activity within 3 months in 55-67\% of the children resistant to the standard doses. In order to achieve the maximal effect, it is reasonable to administer the drug subcutaneously or intramuscularly. At the same time, methotrexate is not indicated for primary therapy in patients with active fever as per recommendations of the American College of Rheumatology [5]. Such patients require genetically engineered biologic drugs. However, in the Russian Federation, tocilizumab and canakinumab - the drugs with proven high efficacy in patients with sJIA - are approved to use only in "children over 2 years of age" as per indications. 
The observed patient featured all the indications to prescription of glucocorticoids for oral intake. However, insufficient efficacy of pulse methylprednisolone therapy indicated steroid resistance, while prescription of glucocorticoids to such a young child would have resulted in the development of severe undesirable phenomena: nanism, physical development lagging, osteoporosis and insuperable steroid dependence.

Analysis of the child's case history, early onset of arthritis, the patient's age, insufficient effect in the setting of pulse methylprednisolone therapy and world experience of methotrexate's application given differences in the drug's absorption between its tableted and parenteral forms and dose-dependent effect in particular, substantiated prescription of methotrexate in the dose of $25 \mathrm{mg} / \mathrm{m} 2$ of body surface per week parenterally (Metoject, MEDAC, Germany), $10 \mathrm{mg} /$ week subcutaneously $\left(25 \mathrm{mg} / \mathrm{m}^{2}\right.$ of body surface per week). The child did not develop an allergic response to administration of methotrexate and tolerated the drug's administration well.

Fever terminated, duration and intensity of morning stiffness and exudative alterations in knee joints reduced 1 month after the methotrexate therapy had begun. Exudative alterations in ankle and wrist joints and intensity of flexion contractures in knee joints reduced, arthralgiae terminated and laboratory parameters of the disease's activity (ESR, serum level of CRP; see tb.) reduced after 3 months. We registered a 50\% improvement according to the pediatric criteria of the American College of Rheumatology. Acute inflammatory articular alterations terminated and the range of motions in knee and wrist joints increased considerably after 6 months. We registered a $90 \%$ improvement according to the $\mathrm{ACR}^{\text {pedi }}$ criteria and the inactive disease stage. Restriction of extreme motions in knee joints was only minimal and no active inflammation signs were present after 12 months (pic. 4-7). Instrumental methods of examination revealed positive dynamics. The US of knee joints did not reveal free fluid in the upper recess; unevenness of the cortical layer of the joint-forming bones and hyperechoic excrescences in the structure of cartilaginous tissue were less pronounced. The child received methotrexate in the dose of $25 \mathrm{mg} / \mathrm{m}^{2}$ per week in syringes for subcutaneous administration on a regular basis for the subsequent 24 months. The child's condition was characterized as clinical laboratory remission. No side effects of the therapy were registered.

Analysis of the presented clinical case demonstrates successful application of methotrexate for parenteral administration in the dose of $25 \mathrm{mg} / \mathrm{m}^{2}$ of body surface per week for systemic JIA and high safety of methotrexate for use in patients with juvenile arthritis. Methotrexate therapy in the dose of $25 \mathrm{mg} / \mathrm{m}^{2}$ per week for subcutaneous administration allowed not only terminating systemic manifestations of the disease and inflammatory articular alterations, recovering functional activity of the patient, preventing progression of osteochondrous destruction, but also avoiding prescription of glucocorticoids and development of severe hormonal therapy-associated complications in the infant.

Pic. 4 A, B. The patient's general appearance in the setting of parenteral intake of methotrexate in the dose of $25 \mathrm{mg} / \mathrm{m}^{2}$ of body surface per week.

A

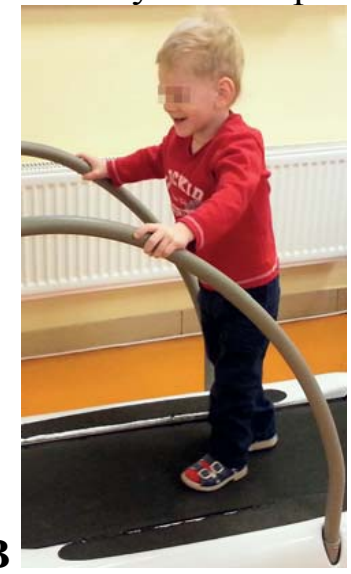


Pic. 5. Lack of swelling in knee and ankle joints in the setting of parenteral intake of methotrexate in the dose of $25 \mathrm{mg} / \mathrm{m}^{2}$ of body surface per week.

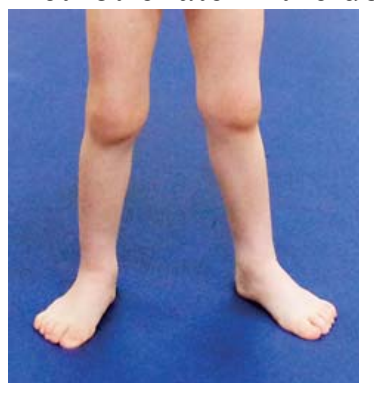

Pic. 6. Functional competence of knee joints in the setting of parenteral intake of methotrexate in the dose of $25 \mathrm{mg} / \mathrm{m}^{2}$ of body surface per week.

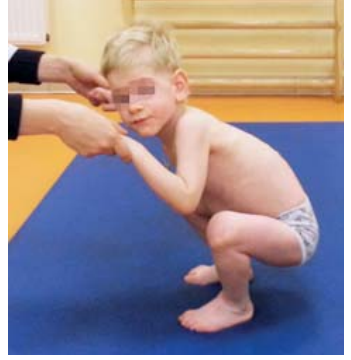

Pic. 7 A, B. Lack of swelling in knee and ankle joints in the setting of parenteral intake of methotrexate in the dose of $25 \mathrm{mg} / \mathrm{m}^{2}$ of body surface per week.

A

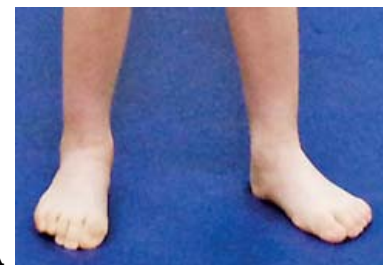

B

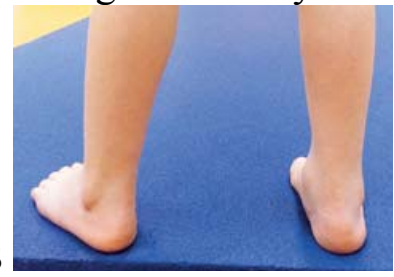

\section{CONCLUSION}

The presented clinical case of early onset of systemic juvenile idiopathic arthritis demonstrates high efficacy of methotrexate therapy in the dose of $25 \mathrm{mg} / \mathrm{m}^{2}$ of body surface per week for terminating systemic manifestations of the disease and acute inflammatory articular alterations.

The choice of treatment tactics was reasonable. Analysis of therapeutic efficacy showed that prescription of methotrexate to a child with a disease taking place for more than 6 months allowed terminating systemic manifestations of the disease after 1 month of treatment, considerably reducing activity of articular syndrome after 3 months and terminating acute inflammatory articular alterations, reducing incapacitation and improving life quality after 6 months. The further use of methotrexate provided termination of recurrence of articular syndrome and systemic manifestations, function recovery in most of the affected joints and normalization of the laboratory parameters of the disease's activity. It should be noted that application of methotrexate allowed avoiding prescription of peroral glucocorticoids and, therefore, avoiding such severe complications as hormone dependence, osteoporosis, sexual and physical development lagging. Treatment results of patient A. allow concluding that prescription of methotrexate in an adequate dose and correct choice of the mode of administration induces remission of the disease, allows achieving remission of the disease and preventing incapacitation in some patients with sJIA.

\section{REFERENCES}


1. Cassidy J., Petty R. Texbook of paediatric rheumatology, 6th ed. Elsevier Saunders. 2011.

2. Alekseeva E. I., Litvitskii P. F. Revmatoidnyi artrit. Etiologiya, patogenez. Klinika. Algoritmy diagnostiki i lecheniya [Rheumatoid Arthritis. Etiology, Pathogenesis. Clinical Picture.

Algorithms for Diagnosis and Treatment]. Moscow, Vedi, 2007. 359 p.

3. Kroot E.J.A., vanLeeuwen M. A., vanRijswijk M. H. et al. No increased mortality in patient with rheumatoid arthritis: up to 10 years of follow-up from disease onset. Ann Rheum Dis. 2000; 59: 954-958.

4. Klinicheskie rekomendatsii. Revmatologiya. Pod red. E. L. Nasonova [Clinical Guidelines. Rheumatology.Edited by E. L. Nasonov]. Moscow, GEOTAR-Media, 2005. pp. 25-71, 120 140.

5. Timothy Beukelman, Nivedita M. Patkar, Kenneth G. Saag, Sue Tolleson-Rinehart, Randy Q. Cron, Esi Morgan Dewitt, Norman T. Ilowite, Yukiko Kimura, Ronald M. Laxer, Daniel J.

Lovell, Alberto Martini, C. EglaRabinovich, NicolinoRuperto. American College of Rheumatology Recommendations for the Treatment of Juvenile Idiopathic Arthritis: Initiation and Safety Monitoring of Therapeutic Agents for the Treatment of Arthritis and Systemic Features. Arthritis Care \& Research. 2011; 63 (4): 465-482.

6. Fleischmann R. Safety and efficacy of disease-modifying antirheumatic agents in rheumatoid arthritis and juvenile rheumatoid arthritis. Expert Opin DrugSaf. 2003; 2 (4): 347-365.

7. Alekseeva E. I., Shakhbazyan I. E. Autoimmunnye bolezni - Autoimmune diseases. 2002; 5: 127.

8. Hashkes P. J., Laxer R. M. Medical treatment of juvenile idiopathic arthritis. JAMA. 2005; 294 (13): 1671-1684.

9. Nasonov E. L. Protivovospalitel'naya terapiya revmaticheskikh boleznei [Anti-inflammatory Therapy of Rheumatic Diseases]. Moscow, M-Siti, 1996. 345 p.

10. Tynjala P., Vahasalo P., Tarkiainen M., Kroger L., Aalto K., Malin M., Putto-Laurila A., Honkanen V., Lahdenne P. Aggressive combination drug therapy in very early polyarticular juvenile idiopathic arthritis (ACUTE-JIA): a multicentrerandomised open-label clinical trial. Ann Rheum Dis. 2011 Sep;70.

11. Sudha Visvanathan, Carrie Wagner, Joseph C. Marini, Daniel J. Lovel, Alberto Martini, Ross Petty, Ruben Cuttica, Patricia Woo, Graciela Espada, Marco Gattorno, Maria T. Apaz, Eileen Baildam, Anders Fasth, Valeria Gerlonil, PekkaLahdenne, Pierre Quartier, RotraudSaurenmann, Suzanne Travers, Alan Mendelsohn, Stephen Xu, Edward H. Giannini, NicolinoRuperto, for the Paediatric Rheumatology International Trials Organization (PRINTO)1 and the Pediatric Rheumatology Collaborative Study Group (PRCSG). The effect of infliximab plus methotrexate on the modulation of inflammatory disease markers in juvenile idiopathic arthritis: analyses from a randomized, placebo-controlled trial. Pediatric Rheumatology. 2010, 8: 24.

12. Alarcon G. S. Methotrexate: Its use for the treatment of rheumatoid arthritis and other rheumatic disorders. In Arthritis and Allied Conditions. A Text book of rheumatology, 13th Edition. Ed. W. J. Koopman. Baltimore, Philadelphia, London: Williams \& Wilkins. 1997; 1: 679-98.

13. Cronstein B. N. The mechanism of action of methotrexate. Rheum Dis Clin North Amer. 1997; 23: 739-755.

14. Tambic-Bukovac L., Malcic I., Prohic A. Personal experience with methotrexate in the treatment of idiopathic juvenile arthritis. Rheumatism. 2002; 49 (1): 20-24.

15. Cassidy J. T. Outcomes research in the therapeutic use of methotrexate in children with chronic peripheral arthritis. J Pediatr. 1998; 133: 179-180.

16. Klein A., Kaul I., Foeldvari I., Ganser G., Urban A., Horneff G. Efficacy and safety of oral and parenteral methotrexate therapy in children with juvenile idiopathic arthritis: an observational study with patients from the German Methotrexate Registry. Arthritis Care Res (Hoboken). 2012 Sep; 64 (9): 1349-56. 
17. Ramanan A. V., Whitworth P., Baildam E. M. Use of methotrexate in juvenile idiopathic arthritis. Arch Dis Child. 2003; 88: 197-200.

18. Yokota S. Classification and treatment strategy for juvenile idiopathic arthritis. Therapy. 1999; 81: 766-772.

19. Giannini E. H., Brewer E. J., Kuzmina N. et al. Methotrexate in resistant juvenile rheumatoid arthritis. Results of the USA-USSR double-blind, placebo-controlled trial. The Pediatric

Rheumatology Collaborative Study Group and The Cooperative Children's Study Group. N Engl J Med. 1992; 326: 1043-1049.

20. Woo P., Southwood T. R., Prieur A. M. et al. Randomized, placebocontrolled, crossover trial of low-dose oral methotrexate in children with extended oligoarticular or systemic arthritis. Arthr Rheum. 2000; 43 (8): 1849-1857.

21. Silverman E., Mouy R., Spiegel L. et al. Leflunomide or methotrexate for juvenile rheumatoid arthritis. $N$ Engl J Med. 2005; 352: 1655-1666.

22. Albertioni F., Flato B., Seideman P. et al. Methotrexate in juvenile rheumatoid arthritis. Evidence of age dependent pharmacokinetics. Eur J Clin Pharmacol. 1995; 47 (6): 507-511. 23. Tukova J., Chladek J., Nemcova D. et al. Methotrexate bioavailability after oral and subcutaneous dministration in children with juvenile idiopathic arthritis. Clin Exp Rheumatol. 2009; 27 (6): 1047-1053.

24. Ruperto N., Murray K. J., Gerloni V. et al. A randomized trial of parenteral methotrexate comparing an intermediate dose with a higher dose in children with juvenile idiopathic arthritis who failed to respond to standard doses of methotrexate. Arthritis Rheum. 2004; 50: 2191-2201. 25. Alsufyani K., Ortiz-Alvarez O., Cabral D. A. et al. The role of subcutaneous administration of methotrexate in children with juvenile idiopathic arthritis who have failed oral methotrexate. $J$ Rheumatol. 2004; 31 (1): 179-182.

26. Kugathasan S., Newman A. J., Dahms B. B. et al. Liver biopsy findings liver in patients with juvenile rheumatoid arthritis receiving long-term, weekly methotrexate therapy. J Pediatr. 1996; 128 (1): 149-151.

27. CronR. Q., Sherry D. D., Wallace C. A. Methotrexate-induced hypersensitivity pneumonitis in a child with juvenile rheumatoid arthritis. J Pediatr. 1998; 132 (5): 901-902. 